\title{
TEORIA GERAL DOS CONTRATOS EMPRESARIAIS, DE PAULA FORGIONI
}

\author{
GENERAL THEORY OF BUSINESS CONTRACTS, BY PAULA FORGIONI
}

FORGIONI, Paula. Teoria Geral dos Contratos Empresariais. São Paulo: Revista dos Tribunais, $2^{\mathrm{a}}, 2011$, p. $23-54$.

\section{Luciano Do Nascimento Costa ${ }^{1}$}

A presente obra trata, inicialmente, acerca dos contratos empresariais no âmbito da ordem jurídica do mercado. A autora afirma que os entes que atuam no mercado são desenvolvidos através de suas próprias relações. Nesse sentido, as empresas atuam, essencialmente, por meio dos contratos, os quais têm por função principal a de impulsionar a circulação de bens e de serviços no mercado, além da função de fomentar a circulação de valores.

De acordo com João Pedro Barroso, o elemento da empresarialidade é fundamental, considerando-se a organização dos elementos de produção é direcionada para a produção e a circulação de bens ou de serviços através de empresas que procurem o lucro. Nesse sentido, o elemento empresarial enseja características próprias aos contratos empresariais, distinguindo-os os demais contratos no ramo do Direito.

Nesse contexto, o tráfico mercantil é efetuado através dos contratos, fazendo a autora um questionamento a respeito do papel do Direito nesse panorama. Assim, refere a autora que a empresa estabelece contratos com os mais distintos agentes econômicos, sendo eles trabalhadores, o Estado, os consumidores ou afins.

Ocorre que, para cada assunto específico, existirá um determinado tratamento jurídico, que dependerá de diferentes fatores. Os contratos empresariais, de um modo bem específico, caracterizam-se como aqueles em que os polos da relação jurídica priorizam a obtenção de lucro.

Dependendo da natureza do contrato, conforme mencionado por João Pedro Barroso, algumas regras eram adotadas para demonstrar a condição das partes contratantes. Dentre essas regras estão as seguintes: a) as partes têm conhecimento a respeito das problemáticas econômico-

1 Advogado. Bacharel em Direito pela Universidade Federal da Bahia-UFBA e Bacharel Interdisciplinar em Humanidades com ênfase em Estudos Jurídicos pelo Instituto de Humanidades, Artes e Ciências da Universidade Federal da Bahia - UFBA. Aprovado nas Especializações Gestão de Projetos, pela Universidade Estadual de São Paulo- USP, pela ESAQ e na Especialização em Direito Público pela Universidade Católica de Minas Gerais-PUCMG. Integrante permanente do Grupo de Pesquisa, Controle de Constitucionalidade da Universidade Federal da Bahia. Coordenador de Informações Fiscais da Prefeitura Municipal de Camaçari e mestrando do Programa de PósGraduação em Direito da Universidade Católica de Salvador-BA. Email: lucianocostasefaz@gmail.com 
financeiras, com capacidade para analisar o negócio jurídico objeto do contrato; b) as partes estão bem assessoradas, com pessoas competentes; c) geralmente as partes já efetuaram investigações independentes sobre o negócio que pretendem realizar.

Contudo, essa visão do mercado acaba por desembaralhar um ponto de vista jurídico pouco comum, uma vez que considera somente os contratos estabelecidos entre as empresas como contratos objeto do direito comercial e que põe em destaque a necessidade de uma teoria geral que analise as peculiaridades dos contratos dentro de um mercado.

Forgioni afirma que os contratos dos consumidores não fazem mais parte do direito comercial, posto que o Direito do Consumidor passou a ser um ramo autônomo do Direito Civil. Atualmente, o contrato empresarial necessita que o vínculo jurídico seja estabelecido entre as empresas. Assim, por se tratar de um vínculo relacionado à atividade empresarial, não pode ser submetido à lógica consumerista.

Em uma diferenciação entre contrato civil e contrato empresarial, menciona Rita Ellert que aquele é celebrado com qualquer pessoa que tenha capacidade civil para tanto, sendo este celebrado entre empresários dentro de suas atividades empresariais. Por esse motivo, os contratos empresariais incitam a industrialização, a produção, a comercialização e a intermediação de produtos e de serviços no mercado.

Nesse contexto, afirma Forgioni que os comercialistas focam suas atenções para os contratos interempresariais, que correspondem aos instrumentos jurídicos celebrados entre as empresas, o que vincula um viés particular aos negócios estabelecidos entre os empresários.

De qualquer modo, nos contratos empresariais devem constar, como referido por Rita Ellert, os elementos essenciais presentes no artigo 104 do Código Civil, quais sejam, o agente capaz, o objeto lícito, possível e determinado ou determinável e a forma prescrita ou não defesa em lei. Ademais, são também elementos desse tipo de contrato a vontade das partes, a eventual intervenção estatal e a determinação dos regimes de direito privado nos contratos. Contudo, o próprio Superior Tribunal de Justiça já determinou que os contratos empresariais não sejam tratados da mesma maneira com que são considerados os contratos civis.

Andreza Baggio menciona que, a par do Código Civil, o ordenamento jurídico brasileiro aplica os princípios da função social do contrato, da boa-fé objetiva e da confiança no Código de Defesa do Consumidor, sendo, nesse âmbito, muito debatida a questão da aplicação do CDC às relações jurídicas estabelecidas entre os empresários.

Diante desse contexto, afirma Forgioni que a doutrina está dividida entre os finalistas e os maximalistas. Para os finalistas, não podem ser considerados consumidores aqueles que obtêm bens ou serviços usados em sua atividade profissional. Andreza Baggio pondera que, para a corrente finalista, o consumidor será considerado o destinatário final do produto ou do serviço.

Conforme Andreza Baggio, a corrente maximalista defende que o conceito de consumidor necessita ser interpretado de forma extensiva, sendo o Código de Defesa do Consumidor a norma responsável por tutelar as relações de consumo.Nesse diapasão, os maximalistas consideram, conforme Forgioni, o CDC como a norma geral aplicável ao mercado financeiro, com a finalidade 
de tutelar o adquirente e disciplinar a realidade de uma maneira mais ampla.

Existe, ainda, uma terceira corrente doutrinária, como referido por Andreza Baggio, que corresponde à chamada teoria finalista mitigada, para a qual a interpretação acerca do conceito de consumidor por equiparação deverá ser estendida quando houver vulnerabilidade. Nesse sentido, o conceito de consumidor, conforme referido pelo próprio código consumerista, pode ultrapassar os limites estabelecidos pelo artigo $2^{\circ}$ do mencionado diploma legal, o qual considera como consumidor qualquer pessoa que intervenha na relação de consumo, além das vítimas de acidentes de consumo e as pessoas que, de alguma maneira, estejam dispostas a efetuar práticas comerciais e contratuais.

Como exemplo mencionado por Ricardo Lupion, houve julgamento do Superior Tribunal de Justiça que, em sua maioria, decidiu por rechaçar uma interpretação de um contrato empresarial que pudesse ocasionar representações negativas a respeito da realidade empresarial. A decisão optou por prestigiar um exercício empresarial e efetivou o fim de um contrato empresarial que já estava sendo renovado de forma automática.

Como mencionado por Forgioni, a proteção dos agentes econômicos que passam por situações abusivas opera a favor do interesse geral do comércio, impedindo comportamentos oportunistas dos agentes, afetando o andamento das relações econômicas.

Pedro Pinto menciona que são diferentes os contratos celebrados entre empresários individuais ou sociedades empresárias, havendo quatro âmbitos nos quais estão relacionadas as atividades empresárias, sendo eles a atividade capital, correspondente aos contratos bancários de financiamentos, a atividade de insumos, que relaciona-se aos contratos de aquisição de matériasprimas e de insumos, a atividade de trabalho, relativa aos contratos de trabalhos, e, por fim, a atividade de tecnologia, correspondente aos contratos de transferência de tecnologia, de assistência e de knowhow.

Depois da entrada em vigor do Código Civil de 2002, os contratos mercantis passaram a ser classificados em dois diferentes tipos, sendo eles civis ou consumeristas. Os contratos serão regulados pelo Código Civil quando as partes contratantes forem iguais do ponto de vista econômico e não fizerem parte de uma relação de consumo, mas de uma relação empresarial. Outrossim, quando existir o uso de produtos ou de serviços como destinatário final, os contratos serão regidos sob o prisma do Código de Defesa do Consumidor. Assim, com a vigência do Código Civil de 2002, que unificou o Direito Privado, não mais existem diferenças nos regulamentos que regem os contratos civis e os contratos mercantis, estando todos sob a égide do Código Civil.

Diante desse panorama, ainda conforme Pedro Pinto, os contratos empresariais correspondem aos contratos que possuem em seus dois polos empresários, sendo obrigatório que ambas atuem profissionalmente em uma atividade empresarial. São, assim, características dos contratos empresariais a não formalidade, como regra geral, tendo em vista a prática extremamente ágil das relações mercantis, a consensualidade entre as partes, a onerosidade e a necessidade de participação de empresários nos dois polos da relação jurídica contratual.

Os contratos empresariais, conforme Ricardo Lupion, podem ter um importante papel 
dentro das companhias porque caracterizam-se como instrumentos de livre exercício das relações entre as empresas, necessitando-se observar a liberdade existente na autonomia negocial quando se tratar de relações patrimoniais.

Em relação à vinculação das partes contratantes ao que está contido no próprio contrato empresarial, essa problemática corresponde ao acerto ou ao erro das decisões dentro das companhias, no sentido de observar as regras fundamentais da competição nos negócios empresariais. Nesse contexto, a intervenção judicial não pode corresponder à neutralização dos resultados de qualquer decisão empresarial errônea da parte contratante.

Em virtude da interpretação dos contratos empresariais, necessita predominar a autodeterminação do contratante. O direito precisa exigir, assim, um esforço por parte dos empresários, eis que ele é quem tem acesso às informações sobre o conteúdo do contrato.

Cumpre referir que o empresário, por ter como uma de suas funções a contratação, pode efetuar deliberações a respeito do contrato, considerando-se, contudo, que cada empresa tem o seu próprio setor especializado, com profissionais treinados e capacitados para resolver determinados problemas.

Os contratos mercantis são direcionados pelos princípios fundamentais presentes no Direito Contratual, destacando-se o princípio da autonomia da vontade, também conhecido como pacta sunt servanda. Através desse princípio, as partes podem deliberar a respeito do contrato, assumindo-o como uma obrigação apenas em virtude de sua própria vontade.

Existe, contudo, uma limitação ao princípio da força vinculante dos contratos, que corresponde à ocorrência de caso fortuito ou de força maior. Também constitui-se como uma limitação à liberdade de contratar a cláusula rebus sic stantibus, conhecida principalmente como teoria da imprevisão, havendo, portanto, a possibilidade de ser resolvido o contrato quando existir oneração excessiva das prestações contratuais, por uma das partes envolvidas, em virtude de eventos imprevisíveis e extraordinários, que causem benefício em demasia para apenas uma das partes.

Alega Forgioni que a organização do mercado exige uma tutela específica aos consumidores, havendo para os contratos consumeristas uma lógica distinta a ser observada. De uma maneira geral, as combinações estabelecidas são efetuadas de acordo com o status das partes envolvidas na relação jurídica. Os contratos mercantis são, assim, desprendidos do direito comum. 